\title{
Photoadhesive of Acrylates Containing Cross-links of Dipyridyl Disulfide
}

\author{
Masahiro Furutani, Kentaro Nakayama, Kazuki Okuma, and Koji Arimitsu* \\ Department of Pure and Applied Chemistry, Tokyo University of Science, \\ 2641 Yamazaki, Noda, Chiba 278-8510, Japan \\ *arimitsu@rs.noda.tus.ac.jp
}

\begin{abstract}
Diacrylate having a dipyridyl disulfide moiety is synthesized as a cross-linker for photoadhesive materials. The cross-linker has been used with 2-hydroxylethyl acrylate and a photoradical initiator to adhere a glass substrate with various kinds of substrates such as glass, copper, polyvinyl chloride, and aluminum. After $4 \mathrm{~J} / \mathrm{cm}^{2}$ of UV irradiation at a wavelength of $365 \mathrm{~nm}, c a$. 0.3-1.2 MPa of shear stress is recorded with the adhesive samples, which is superior to control adhesive samples having no dipyridyl disulfide moieties. From the results on XPS spectral measurements, it is indicated that both electron-rich sulfur atom and electron-poor nitrogen atom would contribute to the adhesion behavior.
\end{abstract}

Keywords: Photoadhesive, Acrylate, Dipyridyl disulfide, Cross-linker, XPS spectral measurement

\section{Introduction}

Adhesives are one of essential materials for manufacturing industry, especially for that of composite products. Different kinds of parts made from metals, ceramics or polymers (dissimilar materials) are adhered by adhesives, which contributes to designing, processing, and weight saving. For adhesion of two adherends of dissimilar materials [1-5], modification of their surface with laser, plasma or chemicals has been used in general. On the other hand, adhesives having catechol or its analogue moieties have been paid attention, because polymers having catechol moieties show high adhesive strength toward various kinds of aherends [6-9]. Adhesives of this type are inspired by proteins having DOPA residues in adhesive components of mussels [10]. Both the aromatic ring and two hydroxyl groups contribute to interaction toward substrates via hydrogen bonding, $\pi-\pi$ stacking, coordination, and formation of covalent bonds [11].

2-Mercaptopyridine [12] has a similar chemical structure with catechol, while it is not found in chemical structures of natural proteins. Nevertheless, it has a pyridine ring and a sulfur atom, and these chemical moieties would also

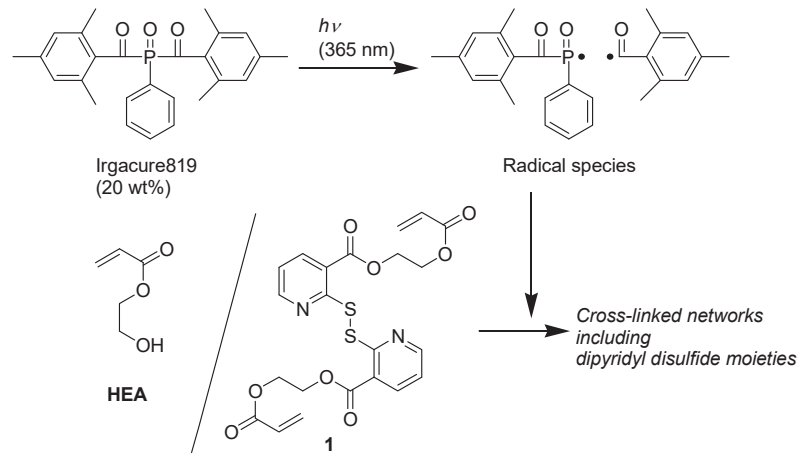

Scheme 1. Radical UV curing system consisting of Irgacure819, HEA and a cross-linker $\mathbf{1}$ for photoadhesion of dissimilar materials.

interact with kinds of adherends including late transition metals. In this work, a disulfide dimer of a 2-mercaptopyridine derivative (1) is used as a diacrylate cross-linker for radical UV curing of 2-hydroxyethyl acrylate (HEA), as shown in Scheme 1. The curing system is applied to photoadhesion of dissimilar materials, which enables to adhere two different substrates quickly and selectively under mild temperature conditions.

\section{Experimental}

2-Mercaptonicotinic acid, thionyl chloride, 
terephthaloyl chloride, triethylamine, and HEA were purchased from Tokyo Chemical Industry Co., Ltd. (Tokyo, Japan). Tetrahydrofran (THF), chloroform, $N, N$-dimethylformamide (DMF), ethyl acetate, hexane, ethanol, sodium hydrogen carbonate, sodium chloride, dichloromethane, and hydrochloric acid (36\% of aqueous solution) were purchased from FUJIFILM Wako Pure Chemical Corporation (Osaka, Japan). Chloroform- $d_{1}$ was purchased from Merck KGaA (Darmstadt, Germany). Irgacure 819 was purchased from Chemische Industrie Basel (Basel, Switzerland). All chemical reagents were used without further purification.

${ }^{1} \mathrm{H}-\mathrm{NMR}$ and ${ }^{13} \mathrm{C}$-NMR spectra were recorded using a JEOL JNM-AL300. FT-IR spectral measurements were performed using a JASCO FT/IR-6600. Photoadhesion was performed with an LED lamp, LPUV365 / 2501-00 (IWASAKI Electric Co., Ltd.). Shear stress was recorded using MCT-1150 (A\&D, Co., Ltd., tensile rate: 10 $\mathrm{mm} / \mathrm{min}$ ). Contact angle of water drop was measured using DMe-211 (Kyowa Interface Science Co., Ltd.). XPS spectral measurement was performed using an AXIS-NOVA (Kratos Analytical Ltd.), employing Al $\mathrm{K} \alpha \mathrm{X}$-rays as the exciting source. The binding energies were referenced to the C $1 \mathrm{~s}$ binding energy, set at 284.8 $\mathrm{eV}$.

Synthesis of 1. To a dried flask were added 2-mercaptonicotinic acid $(0.50 \mathrm{~g}, 3.2 \mathrm{mmol})$, thionyl chloride $(2.7 \mathrm{~mL})$ and DMF $(0.68 \mathrm{~g})$, and stirred at room temperature for $3.5 \mathrm{~h}$. After removal of unreacted thionyl chloride, HEA (1.7 g, $15 \mathrm{mmol})$ in THF $(30 \mathrm{~mL})$ was added to the residue, and the mixture was stirred at room temperature for 5 days. The organic layer was washed twice with brine. Purification was performed after evaporating the solvent with column chromatography (ethyl acetate : hexane $=$ $2: 7, \mathrm{v} / \mathrm{v})$ to obtain 1 in $10 \%$ yield as a white solid $(0.16 \mathrm{~g}) .{ }^{1} \mathrm{H}$ NMR $\left(300 \mathrm{MHz}, \mathrm{CDCl}_{3}\right): \delta 4.55$ $\left(4 \mathrm{H}, \mathrm{m},-\mathrm{CH}_{2}-\right), 4.64\left(4 \mathrm{H}, \mathrm{m},-\mathrm{CH}_{2}-\right), 5.89(2 \mathrm{H}, \mathrm{dd}$, $\left.J=3.0,16 \mathrm{~Hz},-\mathrm{CH}=\mathrm{C}_{2}\right), 6.18(2 \mathrm{H}, \mathrm{dd}, J=3.0$, $\left.4.8 \mathrm{~Hz},-\mathrm{CH}=\mathrm{C}_{2}\right), 6.50(2 \mathrm{H}, \mathrm{dd}, J=4.8,16 \mathrm{~Hz}$, $\left.-\mathrm{C} \underline{\mathrm{H}}=\mathrm{CH}_{2}\right), 7.12(2 \mathrm{H}, \mathrm{dd}, J=3.0,8.0 \mathrm{~Hz}, \mathrm{Py}-\mathrm{H})$, $8.24(2 \mathrm{H}, \mathrm{dd}, J=3.3,8.0 \mathrm{~Hz}, \mathrm{Py}-\mathrm{H}), 8.47(2 \mathrm{H}, \mathrm{dd}$, $J=3.0,3.3 \mathrm{~Hz}, \mathrm{Py}-\mathrm{H}) .{ }^{13} \mathrm{C}$ NMR $(75 \mathrm{MHz}$, $\left.\mathrm{CDCl}_{3}\right): \delta 62,63,120,123,128,132,139,153$, 166, 195, 207. HR-ESI-MS: $m / z$ calcd for $\mathrm{C}_{22} \mathrm{H}_{20}$ $\mathrm{N}_{2} \mathrm{O}_{8} \mathrm{~S}_{2} \mathrm{Na}$ : 527.05588; found: 527.05809.

A diacrylate cross-linker $\mathbf{2}$ is a control compound without a dipyridyl disulfide bond, and a disulfide dimer $\mathbf{3}$ is a model compound of $\mathbf{1}$ for
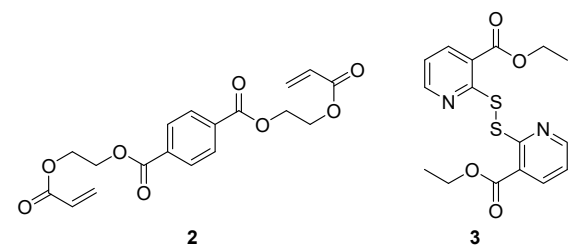

Fig. 1. Chemical structures of compounds 2 and 3.

XPS spectral measurements (Fig. 1).

Synthesis of 2. To terephthaloyl chloride $(0.50$ g, $2.5 \mathrm{mmol})$ were added HEA (2.9 g, $25 \mathrm{mmol})$ and triethylamine $(0.75 \mathrm{~g}, 7.4 \mathrm{mmol})$ in dichloromethane $(20 \mathrm{~mL})$, and the mixture was refluxed for $30 \mathrm{~min}$. The organic layer was washed with $5 \mathrm{wt} \%$ of $\mathrm{HCl}$ aqueous solution, saturated $\mathrm{NaHCO}_{3}$ aqueous solution and brine for twice each. Purification was performed with column chromatography (ethyl acetate) to obtain $\mathbf{2}$ in $63 \%$ yield as a white solid $(0.56 \mathrm{~g}) .{ }^{1} \mathrm{H}$ NMR $\left(300 \mathrm{MHz}, \mathrm{CDCl}_{3}\right): \delta 4.52\left(4 \mathrm{H}, \mathrm{m},-\mathrm{CH}_{2}-\right), 4.60$ $\left(4 \mathrm{H}, \mathrm{m},-\mathrm{CH}_{2}-\right), 5.89(2 \mathrm{H}, \mathrm{dd}, J=1.2,11 \mathrm{~Hz}$, $\left.-\mathrm{CH}=\mathrm{C}_{2}\right), 6.17\left(2 \mathrm{H}, \mathrm{dd}, J=11,16 \mathrm{~Hz},-\mathrm{C} \underline{\mathrm{H}}=\mathrm{CH}_{2}\right)$, $6.48\left(2 \mathrm{H}, \mathrm{dd}, J=1.2,16 \mathrm{~Hz},-\mathrm{CH}=\mathrm{C}_{2}\right) 7.2-7.3$ $(4 \mathrm{H}, \mathrm{m}, \mathrm{Ar}-\mathrm{H}) .{ }^{13} \mathrm{C} \mathrm{NMR}\left(75 \mathrm{MHz}, \mathrm{CDCl}_{3}\right): \delta 62$, $63,126,127,129,131,133,165,166$. HR-ESI-MS: $\quad \mathrm{m} / \mathrm{z}$ calcd for $\mathrm{C}_{18} \mathrm{H}_{18} \mathrm{O}_{8} \mathrm{Na}$ : 385.08994; found: 385.09031 .

Synthesis of 3. 2-Mercaptonicotinic acid $(0.50$ g, $3.2 \mathrm{mmol}$ ) was stirred with thionyl chloride (6 $\mathrm{mL})$ and DMF $(5.3 \mathrm{~g})$ at room temperature for $1 \mathrm{~h}$. After removal of unreacted thionyl chloride, ethanol $(20 \mathrm{~mL})$ was added to the residue, and the mixture was stirred at room temperature for 1 day. Purification was performed after evaporating the solvent with column chromatography (ethyl acetate : hexane $=1: 1, \mathrm{v} / \mathrm{v})$ to obtain 3 in $43 \%$ yield as a white solid $(0.25 \mathrm{~g}) .{ }^{1} \mathrm{H}$ NMR (300 $\left.\mathrm{MHz}, \mathrm{CDCl}_{3}\right): \delta 1.45\left(6 \mathrm{H}, \mathrm{t}, J=6.0 \mathrm{~Hz},-\mathrm{CH}_{3}\right)$, $4.47\left(4 \mathrm{H}, \mathrm{q}, J=6.0 \mathrm{~Hz},-\mathrm{CH}_{2}-\right), 7.11(2 \mathrm{H}, \mathrm{dd}, J=$ $4.5,8.1 \mathrm{~Hz}, \mathrm{Py}-\mathrm{H}), 8.25(2 \mathrm{H}, \mathrm{dd}, J=1.8,8.1 \mathrm{~Hz}$, Py-H), 8.47 (2H, dd, $J=1.8,4.5 \mathrm{~Hz}, \mathrm{Py}-\mathrm{H}) .{ }^{13} \mathrm{C}$ NMR $\left(75 \mathrm{MHz}, \mathrm{CDCl}_{3}\right): \delta 14,62,120,124,139$, $152,159,165$.

Photoadhesion using $\mathbf{1}$ as a cross-linker. Each substrate (glass, polyvinyl chloride (PVC), copper, and aluminum) was used without further pretreatment. HEA, Irgacure $819(20 \mathrm{wt} \%$ toward HEA) and 1 ( $5 \mathrm{~mol} \%$ toward HEA) were dissolved to the least amount of THF (or chloroform in the case of PVC). The solution was dropped each substrate, and sandwiched with a glass substrate (adhesive area: $30 \mathrm{~mm}^{2}$ ). UV irradiation was then performed using a monochromatic light source of $365 \mathrm{~nm}\left(50 \mathrm{~mW} / \mathrm{cm}^{2}, 4 \mathrm{~J} / \mathrm{cm}^{2}\right)$, followed by shear stress measurements. Shear stress was recorded 
several times, and the maximum value was used for comparison of data.

Control experiments of the photoadhesion. HEA, Irgacure 819 (20 wt $\%$ toward HEA) and $2(0$ or $5 \mathrm{~mol} \%$ toward HEA) were dissolved to the least amount of THF. The solution was dropped $\mathrm{Cu}$ substrate, and sandwiched with a glass substrate (adhesive area: $30 \mathrm{~mm}^{2}$ ). UV irradiation was then performed using a monochromatic light source of $365 \mathrm{~nm} \mathrm{(50}$ $\mathrm{mW} / \mathrm{cm}^{2}, 4 \mathrm{~J} / \mathrm{cm}^{2}$ ), followed by shear stress measurements. Shear stress was recorded several times, and the maximum value was used for comparison of data.

Chemical states of dipyridyl disulfide moieties. After shear stress measurement of the glass- $\mathrm{Cu}$ sample using 1, the fracture surfaces were subjected to XPS spectral measurements. For comparison, powder of $\mathbf{3}$ on indium foil was also subjected to the same measurements.

\section{Results and discussion}

3.1. Photoadhesion using 1 as a cross-linker

Quantitative consumption of acryloyl groups was confirmed after $4 \mathrm{~J} / \mathrm{cm}^{2}$ of UV irradiation, by FT-IR spectral measurement (decrease of peak area at $\left.1637 \mathrm{~cm}^{-1}\right)$. The UV-cured products were found to be insoluble to THF. Shear stress of in the range from 0.27 to $1.2 \mathrm{MPa}$ was recorded, and the value for glass was higher than for metals (Fig. 2). Triple value for the glass- $\mathrm{Cu}$ sample comparing with glass-Al sample would indicate better interaction of sulfur (and nitrogen) atoms from 1 with substrate of late transition metals $[13,14]$.

Samples preparing with 1 showed much higher adhesive property than control samples containing 0 or $5 \mathrm{~mol} \%$ of 2 toward HEA (Fig. 3). Shear stress was apt to be kept during extension in the cases of glass-glass samples (Fig. 3(a)). This is probably due to hydrophilic interaction between glass substrate and hydroxyl groups of the adhesive layer. Cross-linker $\mathbf{1}$ would be more hydrophilic than 2, resulting in more than twice value of shear stress. Furthermore, the UV-cured adhesive layer was stretched before breaking of the sample. This would be due to exchange reactions between disulfide bonds [15-17].

On the other hand, the difference was much clear in the cases of glass- $\mathrm{Cu}$ samples. The surface of $\mathrm{Cu}$ was more hydrophobic than of glass, confirmed by measurements of contact angle of water $\left(71^{\circ}\right.$ for $\mathrm{Cu}$ and $39^{\circ}$ for glass). Results

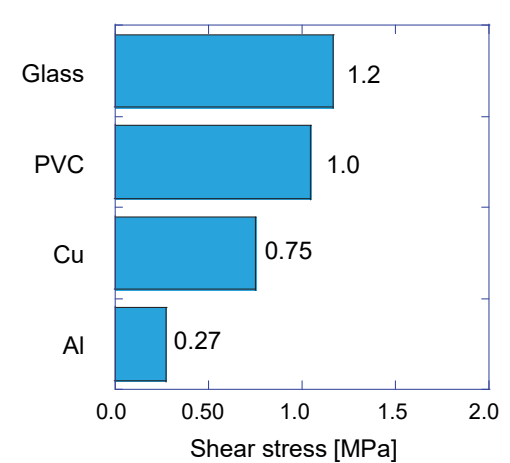

Fig. 2. Maximum shear stress of adhesive samples of 1 fabricated with a glass substrate and another substrate (glass, PVC, $\mathrm{Cu}$ or $\mathrm{Al}$ ).
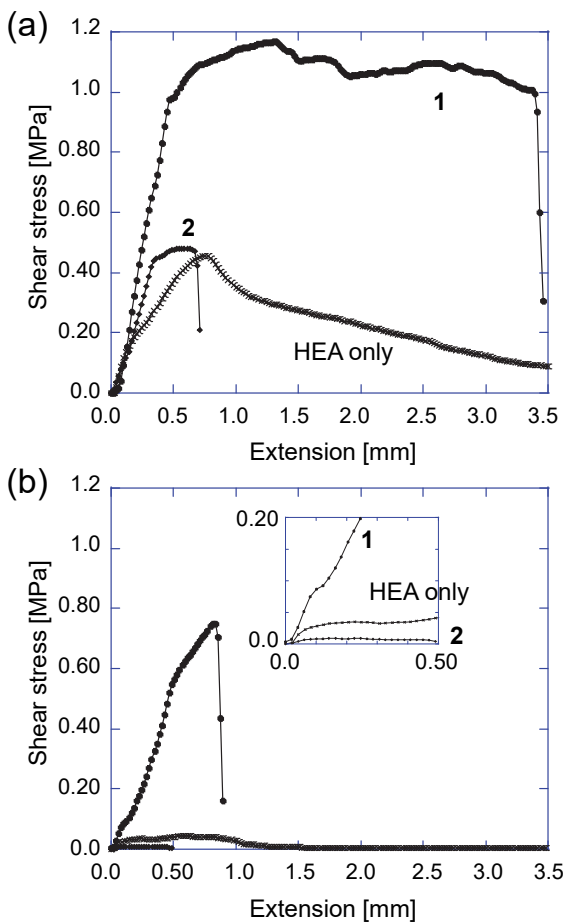

Fig. 3. Shear stress curves of (a) glass-glass and (b) glass-Cu samples as a function of extension.

shown in Fig. 3(b) indicate that cross-linking moieties of 1 would contribute to both cohesion in bulk of the adhesive layer and interaction in the interface. Intertacial fracture was observed on the glass-Cu sample of $\mathbf{1}$, which the UV-cured residue was remained on the glass or $\mathrm{Cu}$ side.

\subsection{Chemical states of dipyridyl disulfide moieties}

To investigate chemical states of the nitrogen and sulfur atoms in the UV-cured sample of $\mathbf{1}$, XPS spectral measurements were performed (Fig. 4). A model compound $\mathbf{3}$ had simple spectral charts where a peak at $398.8 \mathrm{eV}$ for N1s and a peak pair at $163.4 \mathrm{eV}$ for S2p were observed. The former peak is assigned to nitrogen atom of pyridine $[18,19]$. The latter peak pair is assigned to sulfur atom of disulfide [20]. In the N1s spectra of 

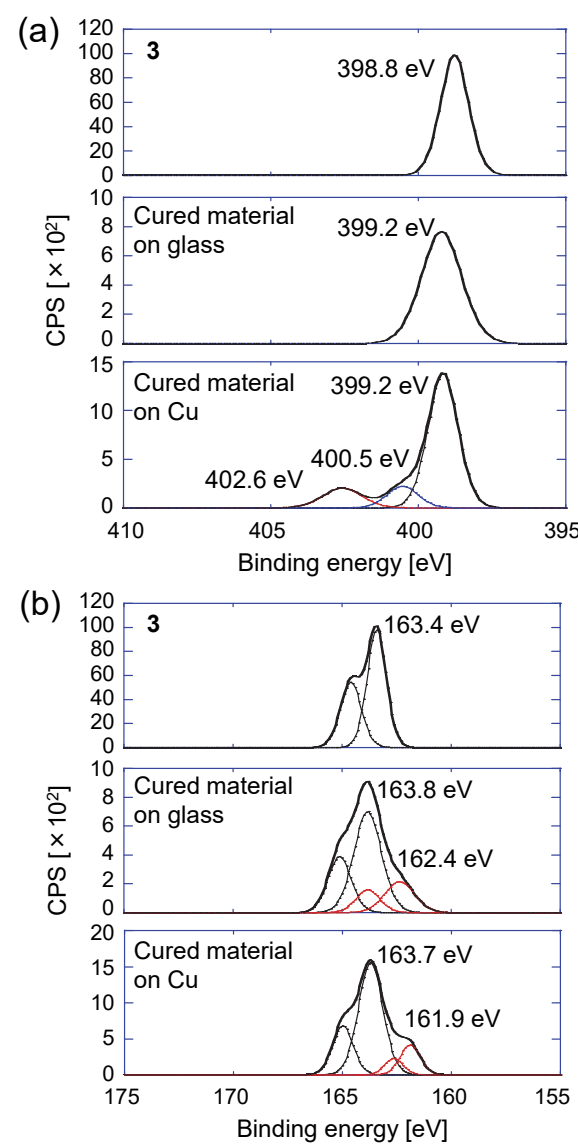

Fig. 4. XPS spectra of (a) N1s and (b) S2p of (upper) 3, and (middle, lower) UV-cured adhesive glass-Cu sample fabricated with 1 .

UV-cured adhesive sample of $\mathbf{1}$, new peaks are observed at 400.5 and $402.6 \mathrm{eV}$ only on the side of $\mathrm{Cu}$ substrate (Fig. 4(a)). This indicates that a part of nitrogen atoms of the dipyridyl disulfide moiety from 1 would interact with the $\mathrm{Cu}$ surface. In comparison, new peaks are observed in the lower binding energy region, around $162 \mathrm{eV}$ in the $\mathrm{S} 2 \mathrm{p}$ spectra of the adhesive sample (Fig. 4(b)). This implies the presence of electron-rich sulfur atoms on the both sides. Although the mechanism for generation of such sulfur atoms is still unknown, these sulfur atoms may contribute to the adhesion via hydrophilic interaction (on the glass side) and coordination (on the $\mathrm{Cu}$ side) [13].

\section{Conclusion}

Dipyridyl disulfide moiety has been integrated in a photoadhesive system, by using compound $\mathbf{1}$ as a cross-linker. The composition had higher values of shear stress than control samples having no dipyridyl disulfide moieties. Glass, PVC or $\mathrm{Cu}$ substrate could be adhered with another glass substrate. XPS spectral measurements revealed change of the chemical state of nitrogen and sulfur atoms. Study for higher adhesive strength with this radical UV curing system is undergoing.

\section{Acknowledgement}

This work was supported by JSPS KAKENHI Grant Number JP18K14007.

\section{References}

1. P. Molitor and T. Young, Int. J. Adhes. Adhes., 24 (2004) 127.

2. J. S. Eom and S. H. Kim, Thin Solid Films, $\mathbf{5 1 6}$ (2008) 4530.

3. A. J. Harris, B. Vaughan, J. A. Yeomans, P. A. Smith, and S. T. Burnage, J. Eur. Ceram. Soc., 33 (2013) 2925.

4. Y. Sugimoto, Y. Nishimura, F. Uehara, and A. Matsumoto, ACS Omega, 3 (2018) 7532.

5. B. Goss, Int. J. Adhes. Adhes., 22 (2002) 405.

6. G. Westwood, T. N. Horton, and J. J. Wilker, Macromolecules, 40 (2007) 3960.

7. D. Payra, Y. Fujii, S. Das, J. Takaishi, and M. Naito, Polym. Chem., 8 (2017) 1654.

8. K. Zhan, C. Kim, K. Sung, H. Ejima, and N. Yoshie, Biomacromolecules, 18 (2017) 2959.

9. S. Wang, Y. Kitamura, N. Hiraishi, S. Taira, A. Tsuge, T. Kaneko, and D. Kaneko, Polymer, 165 (2019) 152.

10. B. P. Lee, P. B. Messersmith, J. N. Israelachvili, and J. H. Waite, Annu. Rev. Mater. Res., 41 (2011) 99.

11. J. Saiz-Poseu, J. Mancebo-Aracil, F. Nador, F. Busqué, and D. Ruiz-Molina, Angew. Chem. Int. Ed., 58 (2019) 696.

12. S. Stoyanov, I. Petkov, L. Antonov, and T. Stoyanova, Can. J. Chem., 68 (1990) 1482.

13. A. Ulman, Chem. Rev., 96 (1996) 1533.

14. R. G. Nuzzo and D. L. Allara, J. Am. Chem. Soc., 105 (1983) 4481.

15. M. Furutani, A. Kakinuma, and K. Arimitsu, $J$. Polym. Sci. A: Polym. Chem., 56 (2017) 237.

16. M. Furutani and K. Arimitsu, J. Adhes. Soc. Jpn., 54 (2018) 302.

17. M. Furutani, K. Endo, and K. Arimitsu, submitted.

18. J. Casanovas, J. M. Ricart, J. Rubio, F. Illas, and, J. M. Jiménez-Mateos, J. Am. Chem. Soc., 118 (1996) 8071.

19. X. Zhou, S. H. Goh, S. Y. Lee, and K. L. Tan, Appl. Surface Sci., 126 (1998) 141.

20. F. Bensebaa, Y. Zhou, Y. Deslands, E. Kruus, and T. H. Ellis, Surface Sci., 405 (1998) L472. 